\title{
Endoscopic perforation during EMR or ESD: who should take care of the patient?
}

\section{다 (요우}

\author{
Authors \\ Mathieu Pioche, Gaspard Bertrand, Jérôme Rivory \\ Institution \\ Hepatogastroenterology Division, Edouard Herriot \\ Hospital, Lyon, France \\ Bibliography \\ DOI https://doi.org/10.1055/s-0044-101348 | \\ Endoscopy International Open 2018; 06: E313-E314 \\ (c) Georg Thieme Verlag KG Stuttgart · New York \\ ISSN 2364-3722
}

Perforations have always been the pet peeve of endoscopists, inhibiting for years our desire to go off the beaten track of endoluminal endoscopy. Endoscopic submucosal dissection (ESD) and per oral endoscopic myotomy (POEM) opened our eyes to the therapeutic field offered by submucosal tunneling and also to the lack of clinical consequences when $\mathrm{CO}_{2}$ spread around the bowel tract. Nevertheless, even the best endoscopist will experience unattended perforations and should be prepared to face them at any time and to close them quickly. Thus, in each center, a decision-making process for prevention and management of perforations should be implemented locally and shared with radiologists and surgeons, as recommended by European Society of Gastrointestinal Endoscopy (ESGE) guidelines [1]. For example, prevention begins with $\mathrm{CO}_{2}$ insufflation for all therapeutic procedures because it changes clinical outcomes of perforations [2] thanks to the quicker blood resorption associated with it and its antiseptic effect.

Today, ESGE guidelines [1] are clear and a per procedural perforation, when recognized, should be treated endoscopically to avoid surgery. At a minimum, every endoscopist should attempt closure of the defect with conventional hemoclips [3], over-the-scope clips [4] or suture techniques. When possible, especially early in the learning curve for managing perforations, asking for help from a colleague to close a defect can reduce the anxiety associated with it. In fact, in more than $90 \%$ of cases, per procedural endoscopic closure of perforations is effective and surgery is avoided [5]. After successful immediate endoscopic closure, surgeon intervention is not useful and a computed tomography (CT) scan does not always change further management. Thus, calling the surgeon does not appear necessary when the following conditions are encountered: the lesion is completely resected, the hole is closed with confidence, and the patient has no severe peritoneal symptoms (mild pain is common due to the pneumoperitoneum). In contrast, if the lesion is not fully resected, an opinion from the endoscopist is necessary to determine whether further endoscopic resection appears feasible after closure because clips in the therapeutic field can prevent any further resection. In all cases in which the lesion is inaccessible for endoscopic resection, the patient should be referred for surgery to remove the neoplasia and an early surgery can be discussed to treat both the lesion and the perforation at the same time without waiting for a delayed peritoneal infection.

In the first 4 hours following endoscopy, in case of missed perforation revealed by patient pain, ESGE [1] also recommends returning to the endoscopy theater instead of surgery to attempt endoscopic closure of the hole. Nevertheless, such cases are probably frequently associated with peritoneal contamination and the surgeon should probably be called to ensure close clinical surveillance after closure. After the 4-hour period, a CT scan should be requested to detect pneumoperitoneum in patients who have peritoneal signs of the condition, diagnose remaining leakage, or detect the amount of liquid present and extent of digestive wall thickening. In the report by Tribonias et al. [6], a conservative strategy without either endoscopy or surgery was chosen because the perforation did not seem perfectly complete given a single bubble attached to the colon wall that was seen on CT evaluation. Nevertheless, prophylactic surgery was also an option and the authors emphasized the decision-making process based on the endoscopist's point of view after examination by the surgeon.

Finally, who should make the final decision about whether to perform surgery or proceed with surveillance? Prophylactic surgery for every case of perforation is dangerous and a source of avoidable morbidity, but on the other hand, delayed surgery is probably more difficult and associated with more morbidity 
than an early procedure. Endoscopists can play a role in discussing with surgeons for which patients postponing surgery is appropriate. The decision to proceed with surgery should be made by the physician responsible for performing the procedure. In the case of perforation, surgeons are responsible for adverse events such as peritonitis and shock that occur as a result of a delayed indication for surgery. Thus, when a hole is not closed sufficiently or when peritoneal symptoms appear during the postoperative period, the surgeon should be called to clinically evaluate the patient and to determine whether further surgery is required. After that, the final decision, although taken after a multidisciplinary discussion, lies with the surgeon. Further studies comparing surgery to surveillance in symptomatic patients with incomplete perforation are needed to illuminate the issues in this debate.

To summarize, per procedural management of perforation is now a part of endoscopy procedures and endoscopists should at least be prepared for them, able to make decisions about how to proceed, and attempt closure of these defects with hemoclips. Once a perforation is closed, a patient should be strictly followed up to detect any remaining leakage. In patients who are asymptomatic (or who have few symptoms) after closure, evaluation by the surgeon is not necessarily inevitable. On the other hand, when symptoms occur more than 4 hours after endoscopy, delaying surgery can have a negative impact with a progressive increase in risk of severe peritonitis. Thus, in such cases of "surgical perforations," the surgeon has responsibility for determining the indication for and optimal timing of surgery and whether the endoscopist can participate in the discussion, and the surgeon should be the cornerstone of the decision-making process.
Competing interests

None

References

[1] Paspatis GA, Dumonceau J-M, Barthet M et al. Diagnosis and management of iatrogenic endoscopic perforations: European Society of Gastrointestinal Endoscopy (ESGE) Position Statement. Endoscopy 2014; 46: $693-711$

[2] Baniya R, Upadhaya S, Khan J et al. Carbon dioxide versus air insufflation in gastric endoscopic submucosal dissection: A systematic review and meta-analysis of randomized controlled trials. Clin Endosc 2017; 50: $464-472$

[3] Takamaru H, Saito Y, Yamada M et al. Clinical impact of endoscopic clip closure of perforations during endoscopic submucosal dissection for colorectal tumors. Gastrointest Endosc 2016; 84: 494-502.e1

[4] Parodi A, Repici A, Pedroni A et al. Endoscopic management of Gl perforations with a new over-the-scope clip device (with videos). Gastrointest Endosc 2010; 72: 881-886

[5] Kim JS, Kim B-W, Kim Jl et al. Endoscopic clip closure versus surgery for the treatment of iatrogenic colon perforations developed during diagnostic colonoscopy: a review of 115,285 patients. Surg Endosc 2013; 27: $501-504$

[6] Tribonias G, Dafera N, Manola M-E et al. How familiar are we with decision-making concerning the treatment of perforation after endoscopic mucosal resection (EMR) in the colon? A case report. Endosc Int Open 2018; 06: E308-E312

\section{CORRECTION}

Pioche M, Bertrand G, Rivory J. Endoscopic perforation during EMR or ESD: who should take care of the patient?

Endoscopy International Open 2018; 06: E313-E314. DOI: $10.1055 / \mathrm{s}-0044-101348$

In the above mentioned article was a misspelling in the title. Correct is: Endoscopic perforation during EMR or ESD: who should take care of the patient? 